\title{
Study the role of cervical Cerclage for women with twin pregnancies
}

\author{
Ahmad H. Abdellaah ${ }^{a}$, Mahmuod I. Alrashedy ${ }^{b}$, Mustafa M. Khodary ${ }^{a}$, Soad I. Hussein Ali ${ }^{c}$ \\ ${ }^{a}$ Obstetrics \& Gynecology Department-Faculty of Medicine-South Valley University, Qena, \\ Egypt. ${ }^{\mathrm{b}}$ Obstetrics \& Gynecology Department, Faculty of Medicine-Al-Azhar University, Assiut, \\ Egypt. ${ }^{c}$ Resident of Obstetric and Gynecology -Qena General Hospital, Qena, Egypt.
}

\begin{abstract}
:
Background: The role of first-trimester history-indicated cerclage among women with a twin pregnancy and a history of preterm birth have not been evaluated.

Objectives; to evaluate the value of cervical cerclage in twin pregnancies as regard of Pregnancy outcome

Patients and methods:

This is a prospective cohort study was performed in Obstetrics and Gynecology Department Qena University Hospital, during a period from 1 march 2019 to 1 march 2020". Information about demographic data, medical history, reproductive history, current pregnancy and its complications and delivery and its outcomes are obtained.Clinical examinations, laboratory and ultrasonic assessment of studied group.

Result:98 pregnant women involved in the study andgestational age at delivery of the studied group show that $11(11.2 \%)$ their gestational age at delivery was ranged between $12-<28$ weeks and $25(25.5 \%)$ their gestational Age at delivery was ranged between $28-<37$ weeksand $62(63.3 \%)$ their gestational age at delivery was ranged between 37-40 weeks.

Neonatal deaths of studiedgroupwere17(9.77\%) of total number (174) of newborns of studiedgroup

Conclusion: History-indicated cervical cerclage performed in women with a twin gestation and a history of preterm birth appeared to have an overall positive effect on maternal and neonatal outcomes, as evidenced by significantly reduced rates of PPROM, preterm delivery and neonatal morbidity and mortality. .

Keyword: Cervical cerclage, cervical insufficiency, history-indicated, multiple gestations, preterm delivery, twins.
\end{abstract}

\section{Introduction:}

Since 1980, the twin birthrate has increased $65 \%$, with twins now accounting for 31.1 per 1,000total live births. Although approximately $12 \%$ of singleton infants areborn prior to 37 weeks, almost $60 \%$ of twin pregnancies deliver preterm(prior to 37 weeks), and nearly $12 \%$ deliver very preterm (prior to 32weeks) (Martin et al., 2012). For infants without congenital malformations prematurity is themost significant cause of perinatal mortality in much of the world and isthe major determinant of neonatal and infant morbidity (Hamilton et al., 2015). Twin pregnancies alone are a risk factor for increasing the incidenceof abortion and preterm birth, also history of one previous preterm delivery has beenshown to associate with a recurrence risk of 17 to $40 \%$.

True cervical insufficiency is important cause of mid-trimesterabortion and preterm birth, and suspected with history of miscarriage in the secondtrimester,orprevious delivery before 34weeks of pregnancy, or cervical shortening in the current pregnancy befor 24 weeks (Alfirevec et al.,2017). For the purpose of this study cervical cerclage by McDoland technique done to selected 
pregnant women preventable at 12 to 14 weeks before the cervix thins out and continuo up to 37 weeks of gestational age). There are a number of potential complications that may arise during or after surgery. These include: risks associated with regional or general anesthesia, chorioamnionitis, injury to the cervix or bladder, bleeding, cervical dystocia withfailure to dilate requiring cesarean section. The aim of this study is to estimate whether cerclage could extend the prolongation of pregnancy, reduce the risk of preterm birth and improve perinatal outcome in twin pregnancies or not.

\section{Patients and methods:}

.Type of

the study: Prospective cohort study.Study Setting: Obstetrics and Gynecology Department Qena University Hospital.

Inclusion criteria: our study included four groups: $1^{\text {st }}$ group of history of midtrimester abortion or preterm labor, $2^{\text {nd }}$ of twin pregnancies by intra cytoplasmic injection, $3^{\text {rd }}$ of short cervix in current pregnancy, $4^{\text {th }}$ oftwin pregnancies without any risk factor.

Exclusion criteria:Present history of medical diseases, uterineanomalies,premature rupture of membranes, intrauterine fetal death, intrauterine growth retardation.

Sample Size Calculation: all recorded cases from 1 march 2019 to 1 march 2020 who attended to Obstetrics and Gynecology Department Qena University Hospital and were 98 womenpregnant. (19 of them hadtwins without risk factors, 56 had history of preterm Labor or 2nd trimester abortion, 10 had twins by IVF, 13 had cervical incompetence in current pregnancy).

\section{TheStudy}

Instrument:

.Complete history taking including: Personal history, menstrual history, obstetric history, present history of chronic diseases and medication,past history of diabetes or hypertension, surgical

history.

.Examination: General examination, abdominal and local clinical examination, bimanual pelvic examination. .Ivestigations: As transvaginal and transabdominal ultrasonography, complete urine,random blood sugar, kidney and liver function tests.

Do TVS at 8 to 12 weeks of gestational age to detect fetal numbers, viability and anomalies (by the nuchal translucency and nasal bone measurement scan), and uterine anomalies or fibroid, or cervicalincompetence.The length of the cervix as measured by ultrasound has in turn been demonstrated to be a useful tool in the prediction of the risk of preterm delivery (Visintineetal.,2008). All patients willing to participate and fulfilling the inclusion after signing the informed consent form, underwent cervical cerclage at 12-14 


\section{Abdellaah et al (2019)}

gestational age for all of them under general anesthesia using Macdonald's techniques (Owen et al., 2009). Patient advised to decrease physical activity, especially those with physical employment, prolonged periods of standing, or frequent and repetitive lifting, although there are no data to confirm or deny the efficacy of bed rest in such cases (Sosa et al ., 2004).

After discharge they were seen a week later at the antenatal clinic then follow up was conducted for all patients every 2- 4 weeks till 28 weeks then weekly till delivery by reviewing symptoms of preterm labour, PROM, bleeding, fever or bad smell vaginal discharge, follow up should include clinical examination, trans-abdominal ultrasound for fetal biometry, growth problem, amniotic fluid volume and fetal demise, and umbilical Doppler beside biophysical profile. Cerclage stitch was removed if PROM occurred, established preterm labor or when pregnancy reached 37 weeks.At the end of study estimate gestational age at time of delivery, birth weight, perinatal mortality and morbidity in case of twin pregnancies
SVU-IJMS, 2(2): 43-49

alone,or in history with midtrimester abortion, or in history of preterm birth, or short cervix in current pregnancy, or ICSI twin to detect if cervical cerclage has a value or not.

\section{Research outcome measures:Primary:}

whether full term,preterm birth,midtrimester abortion.Secondary:Neonatal mortality, perinatal morbidity,birth weight, NICU admission.

\section{Data management and Statistical}

Analysis: Data collected throughout history, basicClinical examination, laboratoryinvestigations and outcome measures coded, entered and analyzed using Microsoft Excel software. Data were then imported into Statistical Package for the Social Sciences (SPSS version 20.0) (Statistical Packagefor the Social Sciences) software for analysis. According to the type of data qualitative represent as number and percentage, quantitative continues group represent by mean $\pm \mathrm{SD}$. 


\section{Result:}

Table (1):Distribution of studied women(98women) according to patient's demographic data.

\begin{tabular}{|c|c|c|c|c|}
\hline $\begin{array}{l}\text { Age } \\
\text { (years) }\end{array}$ & Number & $\begin{array}{l}\text { Number reached full } \\
\text { term }\end{array}$ & Mean \pm SD & $P$ value \\
\hline $\begin{array}{l}\leq 30 \\
>30\end{array}$ & $\begin{array}{l}44 \\
54\end{array}$ & $\begin{array}{l}28 \\
34\end{array}$ & $\begin{array}{r}33.2 \pm 2.25 \\
41.8 \pm 2.17\end{array}$ & 0.087 \\
\hline \multicolumn{5}{|l|}{ Parity } \\
\hline $\begin{array}{l}\leq 2 \\
>2\end{array}$ & $\begin{array}{l}61 \\
37\end{array}$ & $\begin{array}{l}38 \\
24\end{array}$ & $\begin{array}{l}47.8 \pm 2.15 \\
29.7 \pm 2.35\end{array}$ & 0.066 \\
\hline \multicolumn{5}{|l|}{ BMI } \\
\hline $\begin{array}{l}\leq 32.55 \\
>32.55\end{array}$ & $\begin{array}{l}41 \\
57\end{array}$ & $\begin{array}{l}26 \\
36\end{array}$ & $\begin{array}{l}32.4 \pm 2.33 \\
45.9 \pm 2.21\end{array}$ & 0.11 \\
\hline
\end{tabular}

Table (1) shows demographic data of the studied group. That $\mathrm{P}$ values of age, parity and BMI were more than 0.05 Soage, parity and BMI had had no significant effect on the pregnancy outcome .

Table (2): Neonatal deaths of studied group.

\begin{tabular}{|l|c|c|}
\hline & Number & Percent \\
\hline Neonatal deaths & 17 & $9.77 \%$ \\
\hline
\end{tabular}

Table (2) shows the total number of newborns of studied group was 174 and neonatal deaths was 17 .

Table (3): Comparison between studied groups according to reaching full term.

\begin{tabular}{|l|c|c|c|c|}
\hline \multicolumn{1}{|c|}{ studied groups } & $\begin{array}{c}\text { Twins } \\
\text { without } \\
\text { risk factors }\end{array}$ & $\begin{array}{c}\text { History of } \\
\text { preterm Labor } \\
\text { or 2nd trimester } \\
\text { abortion }\end{array}$ & Twins by IVF & $\begin{array}{c}\text { Cervical } \\
\text { Incompetence in } \\
\text { current } \\
\text { pregnancy }\end{array}$ \\
\hline Total number & 19 & 56 & 10 & 13 \\
\hline $\begin{array}{l}\text { number reached } \\
\text { full term }\end{array}$ & 11 & 36 & 6 & 9 \\
\hline$\%$ & $57.8 \%$ & $64.2 \%$ & $60 \%$ & $69.2 \%$ \\
\hline mean \pm SD & $14.8 \pm 1.87$ & $44.7 \pm 2.14$ & $8.3 \pm 1.76$ & $11.4 \pm 2.71$ \\
\hline P value & 0.0471 & 0.0323 & 0.0368 & 0.0229 \\
\hline
\end{tabular}


Table (3) shows comparison between risk factors groups according to reaching full term,shows $\mathrm{P}$ values of studied groups were less than 0.05 So cervical cerclage had had significant effect on prolongation of period of pregnancywhich improve pregnancy outcome.Cervical cerclage was most effective in group (cervical Incompetence in current pregnancy) as $69.2 \%$ of them reached full term, then group(history of preterm Labor or 2nd trimester abortion) as $64.2 \%$ of themreached full term,

\section{Discussion:}

Preterm labour remains a difficult problem to prevent, stop or even delay in higher order pregnancies. Cervical cerclage has reduced the risk of preterm labor (PTL) for selected population of singleton pregnancies as those with history of preterm birth and a shortened cervix (Liu et al., 2015)

Moreover, routine prophylactic CC has been approached as a policy for prolonging gestation, and some evidence exists the suggesting that its routine use in twin pregnancies is beneficial (Obeidat et al., 2017). This is why this study was selected to be conducted to evaluate the value of cervical cerclage in twin pregnancies as regard of Pregnancy outcome (prolongation of pregnancy, and decrease the risk of preterm labor). The 2nd objective is to improve perinatal outcomes in women with twinpregnancies. Our results are supported by study of Rottenstreich et al., (2019) as they reported that the age of their studied group was (27-36) years. Abdulmalek,(2019) found that the median gestational age at delivery was $(37+3,35+6,34+5$ weeks $)$ in Group 1, 2, and 3 respectively, Moreover, the majority of Group 1 (93\%), (16\%) of Group
2, and (10\%) of Group 3 were delivered at $>37$ weeks of gestation $(\mathrm{P} \leq 0.001)$ (Group 1 (N-86): Women who received prophylactic CC, Group 2 (N-44): Those who refused the $\mathrm{CC}$ and choice to receive the vaginal progesterone \& Group 3 (N-20): Those who ask for advisement of bed rest and restriction of heavy physical activity. In the study in our hands, women gestational age at delivery was ranged between $28-40$ weeks with a mean value of $34.83 \pm 3.89$ weeks, gestational age at delivery of the studied group show that $11(11.2 \%)$ their gestational age at delivery was ranged between 12-<28 weeks and $25(25.5 \%)$ their gestational Age at delivery was ranged between $28-<37$ weeks and $62(63.3 \%)$ their gestational age at delivery was ranged between 37-40 weeks.Regarding Rottenstreich et al., (2019), the live-birth rate was significantly higher in the cerclage group than in the control group (97.6\% vs 80.5\%; OR, 9.7 (95\% CI, 2.15-43.71); $\mathrm{P}=$ 0.001). All cases of intrapartum stillbirth occurred in pregnancies delivered before 25 weeks;Our study had lower neonatal deaths (9.77\%), so our recommendations are: Further studies on large geographical scale and on larger sample size to emphasize our conclusion, more patients, longer follow-up, 
Abdellaah et al (2019)

and multicenter experience are all necessary to accurately figure out the value of cervical cerclage in twin pregnancies as regard of pregnancy outcome, future studies are warranted to confirm the findings, identify the optimal characteristics of patients with a twin gestation for whom history-indicated cerclage.

\section{Conclusions:}

Cervical cerclage performed in women with a twin gestation with history of preterm birth, 2nd trimester abortion or twin by ICSI or have cervical incompetence or even without any risk factors appeared to have an overall positive effect on maternal and neonatal outcomes, as evidenced by significantly reduced rates of PPROM, preterm delivery and neonatal morbidity and mortality.

\section{Reffrences:}

Abdulmalek I Y, (2019). The benefit of prophylactic cervical cerclage in twin pregnancies. Medical Journal of Babylon, $16(2), 128-13$

Alfirevic Z, Navaratnam K, Mujezinovic F (2017).Amniocentesis and chorionic villus sampling for prenatal diagnosis. The Cochrane Database of Systematic Reviews. John Wiley \&Sons, Ltd. 9: CD003252 Hamilton BE, Martin JA, Osterman MJ, Curtin SC, Matthews TJ. 2015. Births: Final data for 2014. Natl Vital Stat Rep;64:1-64.4. Liu L, Oza S, Hogan D, Perin J, Rudan
SVU-IJMS, 2(2): 43-49

I,Lawn JE, et al.( 2015). Global, regional, and national causes of child mortality in 2000-13, with projections to inform post-2015 priorities: an updated systematic analysis. Lancet; 385:430-440.

\section{Martin JA, Hamilton BE, Osterman} MJK. 2012. Three decades of twin births in the United States, 1980-2009. NCHS Data Brief, no 80. Hyattsville, MD: National Center for Health Statistics;

\section{Obeidat N, Alchalabi H, Obeidat M,} Sallout B, Hamadneh S, Hamadneh J, et al. (2017). Effectiveness of prophylactic cervical Cerclage in prolonging higher-order multiple pregnancies. Sultan QaboosUniv Med $\mathrm{J} ; 17: \mathrm{e} 314-8$.

Owen J, Hankins G, Iams JD, Berghella V, Sheffield JS, et al. (2009) Multicenter randomized trial of cerclage for preterm birth prevention in high-risk women with shortened midtrimester cervical length. Am J

ObstetGynecol 201: 375.

Rottenstreich A, Levin G, Kleinstern G, Zigron R, Rottenstreich M , Elchalal U (2019).History-indicated cervical cerclage in management of twin pregnancy. Ultrasound in Obstetrics \& Gynecology, 54(4),517-523.

Schieve LA, Wright VC, Reynolds MA, JengG(2002); Division of ReproductiveHealth, National Center forChronic Disease Preventionand Health Promotion, Center for Disease Controlan Prevention(CDC).Assisted reproductive 
technology surveillance-UnitedStates, (2002). MMWR SurveillSumm 2005;54:1-24.

Sosa C, Althabe F, Belizan J, BergelE. Bed rest in singleton pregnancies for preventing preterm birth. Cochrane Database Syst Rev 2004:CD003581. J Perinatol 2001;21:444-50.

Visintine J, Berghella V, Henning D, Baxter J(2008). Cervical length for prediction of preterm birth in women 